\title{
Working
}

Paper 
Quantifying Impact of Aging Population on Fiscal Space

Seok Gil Park 


\title{
IMF Working Paper
}

\author{
Fiscal Affairs Department
}

\section{Quantifying Impact of Aging Population on Fiscal Space ${ }^{1}$}

\author{
Prepared by Seok Gil Park \\ Authorized for Distribution by Abdelhak Senhadji
}

June 2012

\section{This Working Paper should not be reported as representing the views of the IMF.}

The views expressed in this Working Paper are those of the author(s) and do not necessarily represent those of the IMF or IMF policy. Working Papers describe research in progress by the author(s) and are published to elicit comments and to further debate.

\begin{abstract}
This paper quantitatively investigates how population aging trend affects fiscal space measured as unused revenue generating capacity by utilizing a standard neoclassical growth model. A calibration exercise for G-7 countries shows that France, Germany and Italy suffer greater revenue impact from a given reduction in hours worked due to their larger government expenditure. Corrective measures such as pension reform and flexible expenditure policy would be required in order to mitigate the impact of aging on fiscal space.
\end{abstract}

JEL Classification Numbers: E60; H0; J11

Keywords: aging; fiscal space; Laffer curve

Author's E-Mail Address: spark@imf.org

\footnotetext{
${ }^{1}$ I am grateful to Jaebin Ahn, Abdelhak Senhadji, Jaejoon Woo, and the seminar participants at the IMF's Fiscal Affairs Department for their helpful comments. Any errors are solely the author's responsibility.
} 


\section{Contents}

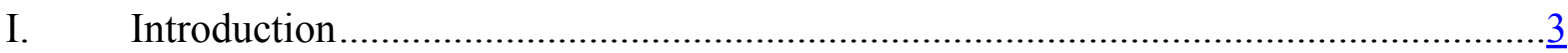

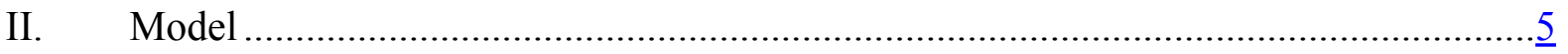

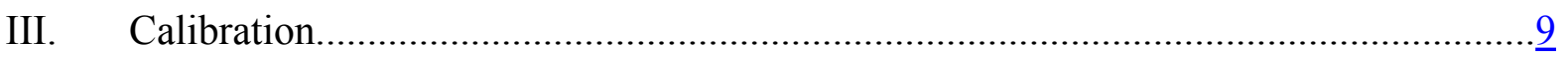

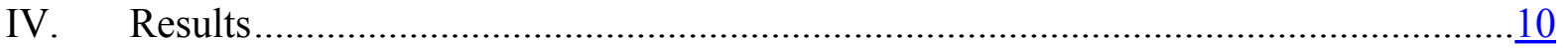

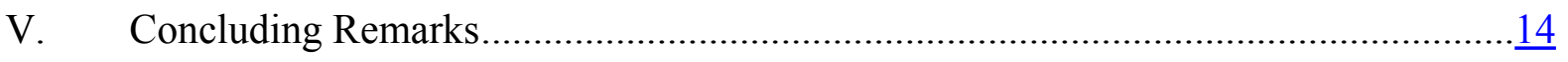

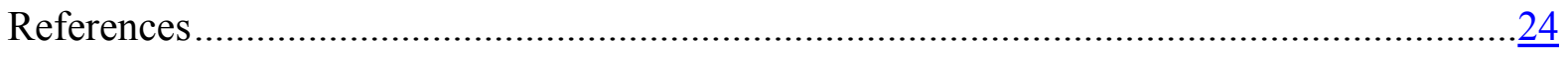

Tables

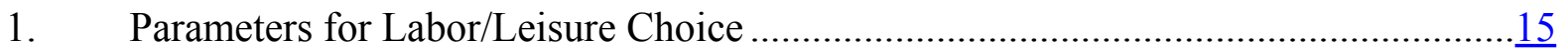

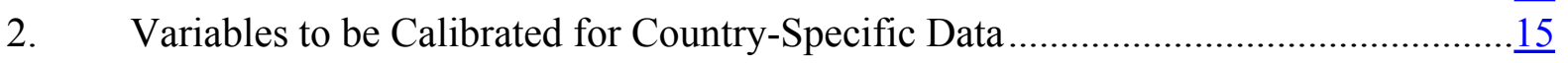

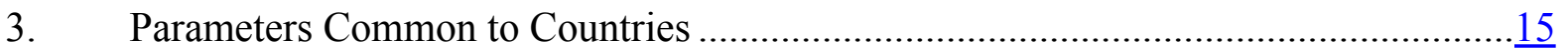

\section{Figures}

1. Hours Worked Per Person and Aging Trend ……..............................................

2. Aging Trend and Changes in Parameters for Labor/Leisure Decision ..........................16

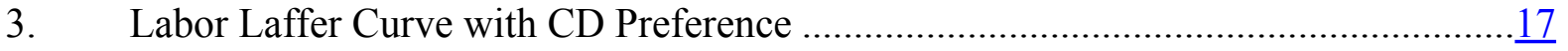

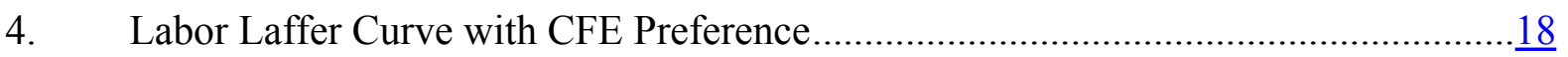

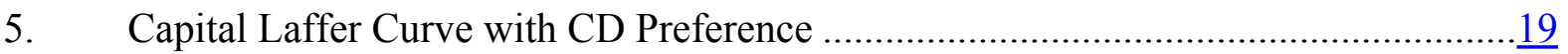

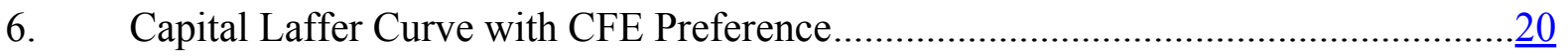

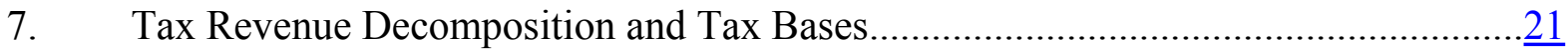

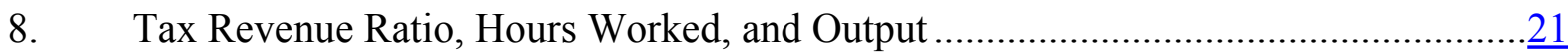

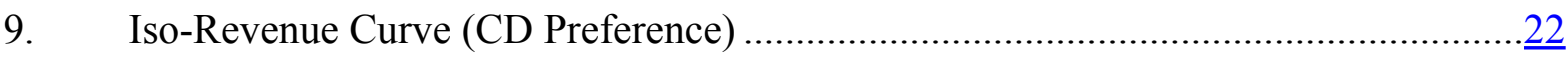

10. Decrease in Fiscal Space vs. Decrease in Labor Supply ............................................ 


\section{INTRODUCTION}

Driven by a lower fertility rate and longer life expectancy, the population of advanced economies is expected to age in the future. Since the aging trend will significantly increase the dependency ratio (proportion of aged population to working population), it may negatively affect macroeconomic performance, including slower growth owing to decreased labor supply and higher fiscal stress from age-related government expenditure. Given fiscal sustainability concerns in advanced economies, the effect of aging on fiscal space warrants careful investigation.

Fiscal space is the available room to maneuver fiscal policy without compromising fiscal sustainability, often regarded as the government's ability to stabilize the value of its debt. In this regard, Ostry et al. (2010) define fiscal space as the distance between current debt levels and the debt limits above which the debt becomes unsustainable based on past fiscal policy. The debt limit (or fiscal limit) ${ }^{2}$ can be estimated using a reduced form model for the fiscal policy reaction function (Ostry et al., 2010), or a stochastic limit can be obtained by calibrating and solving a general equilibrium model ( $\mathrm{Bi}, 2011)$.

Aging trends may affect the primary balance and fiscal space through both government revenue and expenditure. If the aged population works fewer hours, the tax base and revenue may shrink for a given tax rate. Furthermore, a larger old-age group puts pressure on government expenditure via old-age benefits. This paper, however, will focus on the revenue aspect of the aging trend, since flexibility to adjust age-related expenditure is limited politically.

In order to measure fiscal space as unused revenue generating capacity, this paper utilizes the idea of the Laffer curve that suggests a revenue maximizing tax rate exists since tax rates and tax bases have a trade-off relationship. That is, fiscal space in this paper is defined as the distance between the current tax revenue level and the peak of the Laffer curve (maximum revenue). Trabandt and Uhlig (2011) utilized a standard neoclassical growth model where the government imposes distortionary income, capital, and consumption taxes. After deriving a steady state relationship between tax rates and revenues, Trabandt and Uhlig (2011) numerically calculated Laffer curves.

The proposed extension in this paper is to calibrate two sets of steady state equilibria in order to quantify the fiscal impact of aging. The exercise amount to comparing the Laffer curves

\footnotetext{
${ }^{2}$ Leeper and Walker (2011) defined fiscal limit as a point beyond which adjustments in tax rates alone cannot stabilize value of government debt. Since the current status of fiscal policy, whether it is the current debt level or current tax rate, is observable, thus measuring fiscal space is equivalent to measuring the fiscal limit.
} 
derived from the general equilibrium model under the current population and a more aged population. The implications of population aging for individual labor supply decisions (and aggregated labor supply) will be calibrated by adjusting the disutility parameter in labor/leisure choice. A vertical shift of Laffer curves will imply widening fiscal deficits at any given tax rate which implies the fiscal space would be reduced or eliminated as population aging advances. The analysis will be conducted for the G-7 for comparison purposes.

In the aged state based on United Nations World Population Prospects for 2050, the fiscal space of G-7 countries is estimated to shrink between 2.7 percent of baseline GDP (the U.S.) and 7.1 percent of baseline GDP (Italy), when a Cobb-Douglas form utility function is assumed. In response to a given aging shock, the fiscal space of France, Germany, and Italy shrinks more than that of Canada, Japan, and the U.S. owing to the larger size of the government in euro-area countries. Since government expenditure is assumed to grow at a fixed rate regardless of the aging trend, the consumption to output ratio suffers a greater impact from shocks to labor supply and output when the government expenditure to output ratio is greater. As the marginal rate of substitution between leisure and consumption depends on the consumption to output ratio, economies with larger governments are more susceptible to aging shock. Therefore, flexible expenditure policy would be needed in order to mitigate the impact of the aging trend.

Two caveats should be highlighted in the interpretation of results. First, the Laffer curve concept fails to take into account the political aspect of taxation. As countries have different social and political tolerance for taxation, the "effective" maximum on the Laffer curves (i.e., the maximum that is politically feasible) may differ across countries and is likely to lie well below the unconstrained maximum. ${ }^{3}$ Also, society's preference on taxation can change over time as demographics change. Gonzalez-Eiras and Niepelt (2012) showed in their political economy model that aging may boost economic growth.

The second caveat is that the model in this paper excludes corrective policy reaction to the aging trend such as pension reform. Moreover, the labor supply can be affected by factors other than aging, including increased immigration and delay in the retirement age. Actually, the labor force participation rate among the aged population stopped decreasing in the 1980s, and the trend reversed in the 1990s in the U.S. (Maestas and Zissimopoulos, 2010). Karam et al. (2010) showed that pension reforms may increase growth in both the short and long run. In spite of these caveats, this paper's calibration exercise shows how the standard macroeconomic growth model numerically interprets the given demographic projection into a general equilibrium concept.

\footnotetext{
${ }^{3}$ Estimating the effective maximum on the Laffer curves will be challenging.
} 
The remainder of this paper is organized as follows. Section II illustrates a balanced growth model; Section III explains the calibration strategy; and Section IV reports various Laffer curves and explores how the aging trend affects tax revenue. Section V concludes the paper.

\section{MODEL}

The model is a standard neoclassical balanced growth model which is a replication of Trabandt and Uhlig (2011). The representative household chooses consumption $\left(c_{t}\right)$, hours worked $\left(n_{t}\right)$, capital stock $\left(k_{t}\right)$, investment $\left(x_{t}\right)$, and government bonds holdings $\left(b_{t}\right)$ in order to maximize discounted expected utility from consumption, leisure, and exogenous government expenditure $\left(g_{t}\right)$ as in (1) to (3).

$$
\max _{\left\{c_{t}, n_{t}, k_{t}, x_{t}, b_{t}\right\}} E_{0} \sum_{t=0}^{\infty} \beta^{t}\left[u\left(c_{t}, n_{t}\right)+v\left(g_{t}\right)\right]
$$

subject to

$$
\begin{gathered}
\left(1+\tau_{t}^{c}\right) c_{t}+x_{t}+b_{t}=\left(1-\tau_{t}^{n}\right) w_{t} n_{t}+\left(1-\tau_{t}^{k}\right)\left(d_{t}-\delta\right) k_{t-1}+\delta k_{t-1} \\
+R_{t} b_{t-1}+s_{t}+\Pi_{t}+m_{t}, \\
k_{t}=(1-\delta) k_{t-1}+x_{t}
\end{gathered}
$$

where $\beta$ is a discount rate, $\tau_{t}^{c, n, k}$ denotes consumption, labor and capital tax rates. The household's incomes are wages $\left(w_{t}\right)$, dividends for holding capital $\left(d_{t}\right)$, interest earnings from government bonds $\left(\left(R_{t}-1\right) b_{t-1}\right)$, government's subsidies $\left(s_{t}\right)$, firm's profits $\left(\Pi_{t}\right)$, and exogenous payments from (to) foreign countries (net imports, $m_{t}$ ). The previous period's capital depreciates at the rate of $\delta$.

The firm maximizes profits as in (4) with a Cobb-Douglas production function (5).

$$
\max _{\left\{k_{t-1}, n_{t}\right\}} y_{t}-d_{t} k_{t-1}-w_{t} n_{t}
$$

subject to

$$
y_{t}=\xi^{t} k_{t-1}^{\theta} n_{t}^{1-\theta}
$$

where $y_{t}$ denotes output, $\xi$ is total factor productivity, and $\theta$ denotes capital share in the production function. 
The government collects tax revenue $\left(T_{t}\right)$ and spends for expenditure $\left(g_{t}\right)$, subsidy $\left(s_{t}\right)$, and debt services.

$$
\begin{gathered}
g_{t}+s_{t}+R_{t} b_{t-1}=b_{t}+T_{t}, \\
T_{t} \equiv \tau_{t}^{c} c_{t}+\tau_{t}^{n} w_{t} n_{t}+\tau_{t}^{k}\left(d_{t}-\delta\right) k_{t-1} .
\end{gathered}
$$

The output and net import should be allocated to private consumption, investment, and government spending.

$$
c_{t}+x_{t}+g_{t}=y_{t}+m_{t} \text {. }
$$

The optimization conditions from the household and the firm's problems are as follows:

$$
\begin{gathered}
u_{n}(t)=-\frac{\left(1-\tau_{t}^{n}\right) w_{t}}{\left(1+\tau_{t}^{c}\right)} u_{c}(t), \\
E_{t}\left[\beta \frac{1+\tau_{t}^{c}}{1+\tau_{t+1}^{c}} \frac{u_{c}(t+1)}{u_{c}(t)}\left\{\left(1-\tau_{t+1}^{k}\right)\left(d_{t+1}-\delta\right)+1\right\}\right]=1, \\
E_{t}\left[\beta \frac{1+\tau_{t}^{c}}{1+\tau_{t+1}^{c}} \frac{u_{c}(t+1)}{u_{c}(t)} R_{t+1}\right]=1, \\
d_{t}=\theta \frac{y_{t}}{k_{t-1}}, \\
w_{t}=(1-\theta) \frac{y_{t}}{n_{t}}
\end{gathered}
$$

where $u_{c(n)}$ denotes marginal utility from consumption (labor). Equation (9) characterizes the labor supply decision, Equation (10) determines the equilibrium rate of return for capital, and Equation (11) leads to Fisher equation. Equations (12) and (13) are equilibrium factor prices.

The general equilibrium of this model is defined as the path of endogenous variables $y, c, n, k, x, b, d, w, R$ which satisfies the optimization conditions ((9) to (13)), aggregate resource constraint (8), government budget constraint (6), production technology (5), and law of motion for capital (3), given the exogenous variables (tax rates, government spending, net import, and transfer). This paper focuses on the steady state balanced growth equilibria 
where all variables except hours worked, dividend, interest, and tax rates grow at a constant growth rate $\psi\left(\equiv \xi^{1 / 1-\theta}\right)$.

Regardless of the household's preference, equilibrium capital, investment and consumption as a share of output at the steady state is determined by some deep parameters and capital tax rate.

$$
\begin{gathered}
\overline{k / y}=\left(\frac{\bar{R}-1}{\theta\left(1-\bar{\tau}^{k}\right)}+\frac{\delta}{\theta}\right)^{-1}, \\
\overline{y / n}=\overline{k / y^{\frac{\theta}{1-\theta}}}, \\
\overline{x / y}=(\psi-1+\delta) \overline{k / y}, \\
\overline{c / y}=1-\overline{x / y}-\overline{g / y}+\overline{m / y}, \\
\bar{w}=(1-\theta) \overline{y / n}, \\
\bar{d}=\theta \overline{k / y},
\end{gathered}
$$

where $\overline{k / y}$ refers to the steady state capital to output ratio, $\overline{y / n}$ denotes the steady state output to labor ratio, $\overline{x / y}$ is the investment to output ratio, $\overline{c / y}$ is the consumption to output ratio and $\bar{w}$ and $\bar{d}$ are equilibrium factor prices in the steady state. The steady state capital to output ratio is given by the equilibrium rate of return for capital; the production technology determines the steady state output to labor ratio; the steady state investment to output ratio stems from the law of motion for capital; the consumption to output ratio is determined by the aggregate resource constraint.

Since the steady state level of government spending and net import is given exogenously by data, the steady state overall tax revenue to output ratio can be expressed as a function of parameters as in (20).

$$
\begin{gathered}
\overline{T / y}=\tau^{c} \overline{c / y}+\tau^{n}(1-\theta)+\tau^{k}(\theta-\delta \overline{k / y}), \\
\text { Laffer curve: } \bar{T}\left(\tau^{n}, \tau^{k}\right)=\overline{T / y} \times \bar{y} .
\end{gathered}
$$


Then, as the Laffer curve refers to variations in the steady state tax revenue $(\bar{T})$ in response to tax rates, the next step is to solve the steady state output for exogenous variables and parameters. The equilibrium hours worked in the steady state $(\bar{n})$, which depends on the functional form of the household's preference, determines the steady state output through production technology (15).

\section{Cobb-Douglas (CD) preference}

The first example of household's preference is in the Cobb-Douglas form.

$$
u\left(c_{t}, n_{t}\right)=\alpha \log c_{t}+(1-\alpha) \log \left(1-n_{t}\right)
$$

where $\alpha$ governs marginal rate of substitution between consumption and leisure. Obviously, the higher $\alpha$ puts lower weight on leisure and induce to increase labor supply. The $\alpha$ parameter will be used to calibrate the decreased hours worked in aged society. The intertemporal elasticity of substitution is fixed to one, but the Frisch elasticity of labor supply with respect to wage varies with $\alpha$.

The equilibrium hours worked is derived by simultaneously solving the labor supply (9) and labor demand (18). With the Cobb-Douglas preference, an analytical solution exists as follows:

$$
\bar{n}=\left\{1+\frac{(1-\alpha)\left(1+\bar{\tau}^{c}\right)}{\alpha\left(1-\bar{\tau}^{n}\right)(1-\theta)} \frac{(\bar{g}-\bar{m})}{\overline{y / n}}\right\}\left\{1+\frac{(1-\alpha)\left(1+\bar{\tau}^{c}\right)}{\alpha\left(1-\bar{\tau}^{n}\right)(1-\theta)}(1-\overline{x / y})\right\}^{-1}
$$

Since the steady state level of government expenditure and net imports are treated as exogenous parameters, the steady state consumption to output ratio is a function of equilibrium labor in (17).

\section{Constant Frisch Elasticity (CFE) preference}

Although Cobb-Douglas form utility function conveniently generates a closed-form solution for equilibrium labor, the CD preference may have insufficient parameters to be calibrated. The constant Frisch elasticity preference can adjust intertemporal elasticity of substitution and Frisch elasticity of labor. The following specific functional form was utilized in Trabandt and Uhlig (2011).

$$
u\left(c_{t}, n_{t}\right)=\frac{1}{1-\eta}\left\{c_{t}^{1-\eta}\left[1-\kappa(1-\eta) n_{t}^{1+\frac{1}{\varphi}}\right]^{\eta}-1\right\}
$$


where $1 / \eta$ is an intertemporal elasticity of substitution, $\varphi$ is a Frisch elasticity of labor supply. The $\kappa$ parameter governs disutility from working and it will be calibrated for the decreased hours worked in aged states. The equilibrium labor is numerically solved from (9), (17), and (18).

\section{Calibration}

The model is calibrated for G-7 countries using annual data from 1995 to 2009 . The key parameter from data is hours worked per person which is calculated as follows:

$$
\frac{\text { Annual hours worked per worker }}{365 \times 14} \times \frac{\text { Working population }}{\text { Total population }}
$$

The data is from OECD labor force statistics and working population's age ranges from 15 to 64 years. The representative household allocates their working members' 14 hours to work or to leisure. Although the working members of the household choose to work the same hours, if the ratio of working members to non-working members of the household decreases, then the overall average hours worked per person for the household decreases.

Figure 1 describes the projected aging trend of G-7 countries and the projected hours worked per person in aged state (which is assumed to be the state in 2050). The work population ratio in aged state utilizes the UN World Population Prospects 2010 Revision. Since the hours worked per worker is assumed to remain the same in both the current and the aged state, variations in hours worked per person only attribute to the aging trend.

Table 1 shows the calibrated values of disutility weight parameters for work/leisure choice. Since the representative agent appreciates leisure more with smaller $\alpha$, thus smaller values for marginal rate of substitution between consumption and leisure in the CD preference matches expected decreases in hours worked in aged society. Meanwhile, higher $\kappa$ induces the agent work less in aged society in the CFE preference. Figure 2 illustrates the relationship between projected decreases in labor supply and calibrated changes in parameters. The left panel shows that decreases in labor supply is almost linearly mapped into changes in $\alpha$.

Calibrating aging trends with preference parameters is a convenient reduced-form approach for a benchmark projection. That is, the crucial assumption in this calibration is that the working members of the representative household work the same hours per worker regardless of the household's age structure. Therefore, the labor supply projection only depends on the projected dependency ratio in this paper. On the other hand, Gonzales-Eiras and Niepelt (2012)'s overlapping generations model incorporates young worker's endogenous decision on hours worked, which depends on a few additional parameters including the labor productivity of an old generation relative to a young generation, public investment's 
productivity, and political influence of an old generation. Instead of adding possible noises from additional parameters to be calibrated, this paper's approach can be proposed as a benchmark case that can be conveniently utilized for cross-country comparison.

Other key parameters are consumption, labor income, and capital income tax rates. The effective average tax rates are calculated following Trabandt and Uhlig (2011). Specifically, tax revenues are divided by tax bases and the methodology follows Mendoza et al. (1994). Various tax revenues (income tax of individual and corporate, social security contributions, taxes on payroll, recurrent taxes on immovable property, taxes on financial and capital transactions, taxes on goods and services including VAT and sales tax, and excises) are from OECD Revenue Statistics. Tax base data series are from OECD National Accounts database (wages and salaries of household and non-profit institutions, property income, operating surplus and mixed income, durable consumption, and compensation of government employees); the AMECO database of the European Commission (net operating surplus); and IMF's World Economic Outlook (WEO) database (private consumption, and public consumption expenditure). Table 2 shows the effective tax rates which are averages of annual rates from 1995 to 2009.

Table 3 shows six deep parameters that are common to countries. In the balanced growth path, the variables annually grow by 2 percent $(\psi)$; the nominal interest rate is set to 4 percent $(\bar{R})$, the capital share in the Cobb-Douglas production function is 38 percent $(\theta)$; the capital is depreciated at the rate of 7 percent $(\delta)$. Following Trabandt and Uhlig (2011), the household's preference parameters are set to be standard; the Frisch elasticity is assumed to be one $(\varphi)$ and the intertemporal elasticity of substitution is $0.5(\eta)$.

\section{Results}

A general definition of fiscal space is a room to maneuver fiscal policy without compromising fiscal sustainability. As the general definition is obscure, specific definition or calculation of fiscal space can be varied depending on which aspect of fiscal policy we focus on; revenue generating capacity, flexibility to cut expenditure, or the government's indebtedness. For example, Ostry et al. (2010) defined fiscal space as distances between the current debt level and the debt limit implied by the historical adjustments of fiscal balance. That is, Ostry et al. (2010)'s definition fixes the fiscal balance's behavior to the historical pattern and measures fiscal space with the debt level.

This paper defines fiscal space as a distance between the current revenue and the peak of Laffer curve. This type of definition abstracts from the government's indebtedness and expenditure policy and focuses only on how much the country can raise additional revenue in order to finance any projects. Since the aging trend may pose concern on revenue capacity 
through decreased labor supply and production, the distance to peak of Laffer curve is more appropriately measured to access the impact of the aging trend on the fiscal space.

Figure 3 shows the seven countries' labor tax Laffer curves in the current and in 2050's states with the Cobb-Douglas preference. The labor Laffer curve fixes the capital tax rate and varies effective labor tax rate in order to show concave relationship between the labor tax rate and total tax revenue. The $\mathrm{Y}$ axis is scaled as a percent of benchmark revenue which is the total revenue under the current effective tax rates. For example, in the U.S.'s current states, the total tax revenue can increase up to 117.5 percent of the current revenue by raising the labor tax rate to 54 percent. The aging vertically shifts down the labor Laffer curve and the fiscal deficit will be wider at any given tax rates. Italy and Japan are two countries which have largest aging impact. The revenue maximizing labor tax rates are not significantly different between the current and aged states.

The labor Laffer curve from constant Frisch elasticity preference measures the unused fiscal space in a greater amount than Cobb-Douglas preference does. For example, in CFE Laffer curve, the U.S.'s tax revenue can reach up to 128 percent of the current revenue by raising the effective labor tax rate. Although the shapes of Laffer curves are different between two preference assumptions, cross-country patterns are similar in Figures 3 and 4.

Figures 5 and 6 show the capital tax Laffer curves. Unlike the labor Laffer curve, the capital Laffer curve is flat for the lower capital tax rate and the curves are asymmetric around the peaks. In other words, the simulation results show that capital tax rate hikes cannot generate significant additional revenue in every G-7 country. The U.S. has larger fiscal space in capital taxation than the other countries, and Germany's fiscal space is tight although Germany's current effective capital tax rate is relatively low.

The intuition on shapes of Laffer curves can be explained by Figures 7 and 8 . Figure 7 decomposes tax revenue and shows tax bases (consumption and taxable income for labor and capital) of the U.S. case in CD preference. In general, concave shapes of Laffer curves stem from trade-off between tax rates and taxable bases. For example, in the left panels of Figure 7, as labor tax rate increases, the labor tax base (labor income $\bar{w} \bar{n}=(1-\theta) \bar{y}$ ) decreases with reduced equilibrium labor hours. The labor tax base and labor tax rate have an almost linear relationship, thus the multiplication of two linear factors with opposite slopes $\left(\tau^{n}\right.$ and $\left.\bar{w} \bar{n}\right)$ generates a symmetric inverse-U shape curve for labor tax revenue. It is apparent in the upper-left penal of Figure 7 that the labor revenue curve will dominate the overall shape of total revenue curve (Laffer curve).

The right panels of Figure 7 illustrate why the capital tax Laffer curve is asymmetric and flat for the lower tax rates. First, since the capital tax base $(\overline{d k}-\delta \bar{k}=\theta \bar{y}-\delta \bar{k})$ does not decrease over the capital tax rate for lower tax rates and abruptly decreases for higher rates, the capital tax revenue curve is negatively skewed. This pattern stems from the depreciation 
deduction of capital income tax; the capital tax revenue cannot be raised significantly through the rate hike (in the lower level of rates) because the deduction itself grows fast as well when the capital tax rate is lower (thus higher level of capital and depreciation).

Figure 8 further clarifies the intuition behind the shapes of Laffer curves in the U.S. case with $\mathrm{CD}$ preference. The upper panel illustrates how the tax revenue to output ratio (revenue ratio) varies with labor and capital tax rates, and the lower panel shows output and hours worked both in current and aged states. Since the Laffer curve $(\bar{T})$ is the multiplication of revenue ratio $(\overline{T / y})$ and output level $(\bar{y})$, the concave shapes of Laffer curves can be also explained by trade-off between the two factors.

While the capital and consumption tax revenue ratio remain almost the same for various labor tax rates, the labor tax revenue ratio linearly increases with labor tax rate because of the well-known feature of Cobb-Douglas production function; a fixed labor income share to output $(1-\theta)$. However, in the capital tax case, the capital tax revenue rises at slower pace when the rate remains in the lower range. Again, this convexity (of capital tax revenue ratio) stems from the depreciation deduction. Therefore, if the depreciation rate is assumed to be zero $(\delta=0)$, then the capital tax revenue ratio $\left(\tau^{k}(\theta-\delta \overline{k / y})\right)$ will be linear to the capital tax rate and the capital Laffer curve will be a symmetric inverse-U shape as labor Laffer curve.

Also, Figure 8 illustrates how the aging trend affects fiscal space. In the upper panel of Figure 8 , the revenue ratios do not change noticeably with aging because the output falls as the tax bases decreases by aging trend. Instead, the channel through which aging affects fiscal apace is the decreased hours worked and output.

In order to fully maximize revenue, we may want to adjust both the labor and capital tax rates simultaneously. Figure 9 illustrates contour lines of 'Laffer hill' or iso-revenue curves of G-7 countries. The blue vertical and horizontal lines represent the current effective average tax rates. In every case except Germany, the countries may increase revenue by raising the labor tax rate and cutting the capital tax rate.

However, there are two caveats for interpretation. First, as Trabandt and Uhlig (2011) pointed out, the peak of Laffer curve (or hill) does not necessarily maximize the agent's welfare, thus we do not imply a policy move that raises labor tax rate and cuts capital tax rate will be optimal. The peak of Laffer curve (or hill) only represents a revenue maximizing point under a classical growth model. Second, since the consumption tax rate and base does not possess a Laffer curve style trade-off relationship, the model implies that governments can raise revenue without limitation by increasing the consumption tax rate. 
The final and one of the most important results are illustrated by Figure 10. The figure maps the labor supply shocks from aging to declines in the fiscal space (vertical shift of the peak of Laffer hills). First, the fiscal space shrinks in significant amounts as a share of benchmark GDP, i.e., over -7 percent of benchmark GDP for Italy. However, the results warrant careful interpretation; the figure shows that the unused revenue generation capacity shrinks by those amounts, not the actual revenue. The governments may implement policy measures, such as delaying retirement age, in order to absorb the aging shock. Another caveat for interpretation is that changes in fiscal space were measured with the benchmark GDP (from the current steady state). Since the revenue to output ratio does not significantly change with aging, difference in fiscal space measured by respective GDP (comparing current revenue in percent of current GDP and future revenue in percent of future GDP) will not be significant.

Another notable result is the sensitivity of changes in fiscal space with respect to labor supply shocks from aging. The straight lines in Figure 10 represent least square trend lines and the figure shows that euro area countries (France, Germany, and Italy) suffer greater revenue impact from given reduction in hours worked. Two factors explain the phenomenon. First, as the aging affects revenue through decreased output while the revenue ratio is not responsive to the aging shock, the higher revenue ratio of the three countries (with higher effective consumption tax rate) amplifies the effect of output fall on revenue through base effect. The following formula clarifies the point.

$$
\frac{\partial \bar{T}}{\partial \alpha}=\frac{\partial \overline{T / y}}{\partial \alpha}(\approx 0) \bar{y}+\overline{T / y} \frac{\partial \bar{y}}{\partial \alpha} .
$$

The second factor is how much aging shock can alter the marginal utility from consumption, and it depends on the size of government expenditure and net imports. In order to simplify the analytics, the Cobb-Douglas preference is taken as an example. The representative household decides the labor supply by equating marginal disutility from working to marginal utility from consumption. With Cobb-Douglas preference, the labor supply function is as follows:

$$
-\frac{1-\alpha}{1-n_{t}}=\frac{\left(1-\tau^{n}\right) w_{t}}{\left(1+\tau^{c}\right)} \frac{\alpha}{c_{t}},
$$

where the left side is marginal disutility from working, and $\left(1-\tau^{n}\right) w_{t} /\left(1+\tau^{c}\right)$ is the relative price between consumption and labor. The aging shock is calibrated by the decline in the preference parameter $\alpha$, which directly affects the labor supply decision by altering the marginal rate of substitution between consumption and leisure.

The preference parameter also indirectly affects the labor supply decision through the consumption level, since $\alpha$ influences the consumption level and the marginal utility of 
consumption depends on the consumption level as well. This channel stems from the model's general equilibrium feature; when the representative agent finds itself to prefer more leisure, he knows that the one additional unit of consumption will be valued more, as he decreases labor supply and the output and consumption decrease as a result.

When the economies have larger steady state level of government expenditure $(\bar{g})$, then the expenditure to output ratio is more sensitive to given changes in the steady state output which stems from labor supply shock. From the aggregate resource constraints, the consumption to output ratio depends on the government expenditure to output ratio, therefore, the consumption to output ratio is more sensitive to labor supply shock with larger government expenditure.

The crucial assumption for the above-mentioned result is that the government expenditure cannot be adjusted in response to decreased output. Instead, if $\bar{g}$ is flexible to changes in $\bar{y}$ so that government to output ratio is constant, then the consumption to output ratio and marginal utility of consumption will not respond sensitively to the aging shock when the government size is larger.

\section{CONCLUding Remarks}

A standard neoclassical macroeconomic model assesses the significant impact of aging on tax revenue. Notably, it is shown that countries with larger government size (France, Germany, and Italy) are more susceptible to aging shock when government expenditure is assumed to be inflexible. The results imply that corrective policy measures, such as pension reform and flexible expenditure policy, would be required in order to mitigate the impact of aging on fiscal space. 
Table 1. Parameters for Labor/Leisure Choice

\begin{tabular}{l|ccccccc}
\hline & Canada & France & Germany & Italy & Japan & UK & US \\
\hline$\alpha^{1 /}$ in current state & 0.2926 & 0.3090 & 0.2761 & 0.3717 & 0.2974 & 0.2970 & 0.3114 \\
$\alpha$ in aged state & 0.2538 & 0.2770 & 0.2291 & 0.3038 & 0.2305 & 0.2706 & 0.2839 \\
$\kappa^{21}$ in current state & 4.1247 & 4.0380 & 5.0072 & 2.6632 & 3.9948 & 4.1641 & 3.6976 \\
$\kappa$ in aged state & 5.5999 & 5.1879 & 7.5576 & 4.2932 & 6.9049 & 5.1183 & 4.5350 \\
\hline
\end{tabular}

1/ Marginal rate of substitution between consumption and leisure in $C D$ preference.

2/ Disutility weight for labor in CFE preference.

Table 2. Variables to be Calibrated for Country-Specific Data

\begin{tabular}{l|ccccccc}
\hline & Canada & France & Germany & Italy & Japan & UK & US \\
\hline Consumption tax rate & 0.1348 & 0.1954 & 0.1783 & 0.1604 & 0.0730 & 0.1757 & 0.0508 \\
Labor tax rate & 0.2794 & 0.4511 & 0.4074 & 0.4582 & 0.2744 & 0.2706 & 0.2686 \\
Capital tax rate & 0.4277 & 0.3698 & 0.2600 & 0.3592 & 0.4199 & 0.4774 & 0.4049 \\
Gov't spending $^{1 /}$ & 0.1965 & 0.2355 & 0.1903 & 0.1926 & 0.1726 & 0.2004 & 0.1539 \\
Net import" & -0.0312 & -0.0056 & -0.0333 & -0.0129 & -0.0121 & 0.0184 & 0.0359 \\
\hline
\end{tabular}

1/ Share of GDP

2/ Source: Author's calculation utilizing AMECO, OECD and WEO database.

Table 3. Parameters Common to Countries

\begin{tabular}{c|c|c|c|c|c}
\hline$\psi$ & $\bar{R}$ & $\theta$ & $\delta$ & $\varphi$ & $\eta$ \\
\hline 1.02 & 1.04 & 0.38 & 0.07 & 1 & 2 \\
\hline
\end{tabular}


Figure 1. Hours Worked Per Person and Aging Trend

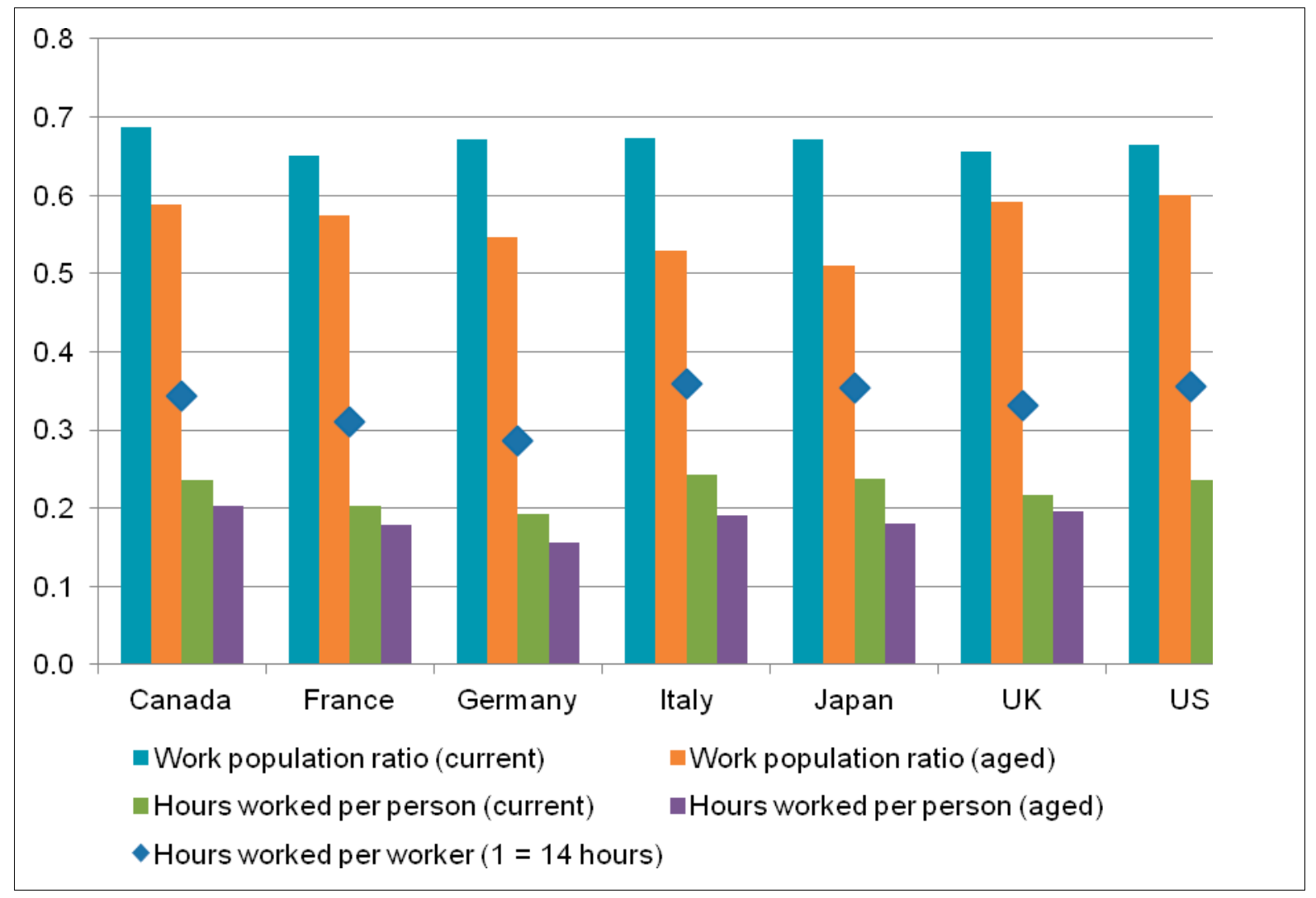

Figure 2. Aging Trend and Changes in Parameters for Labor/Leisure Decision

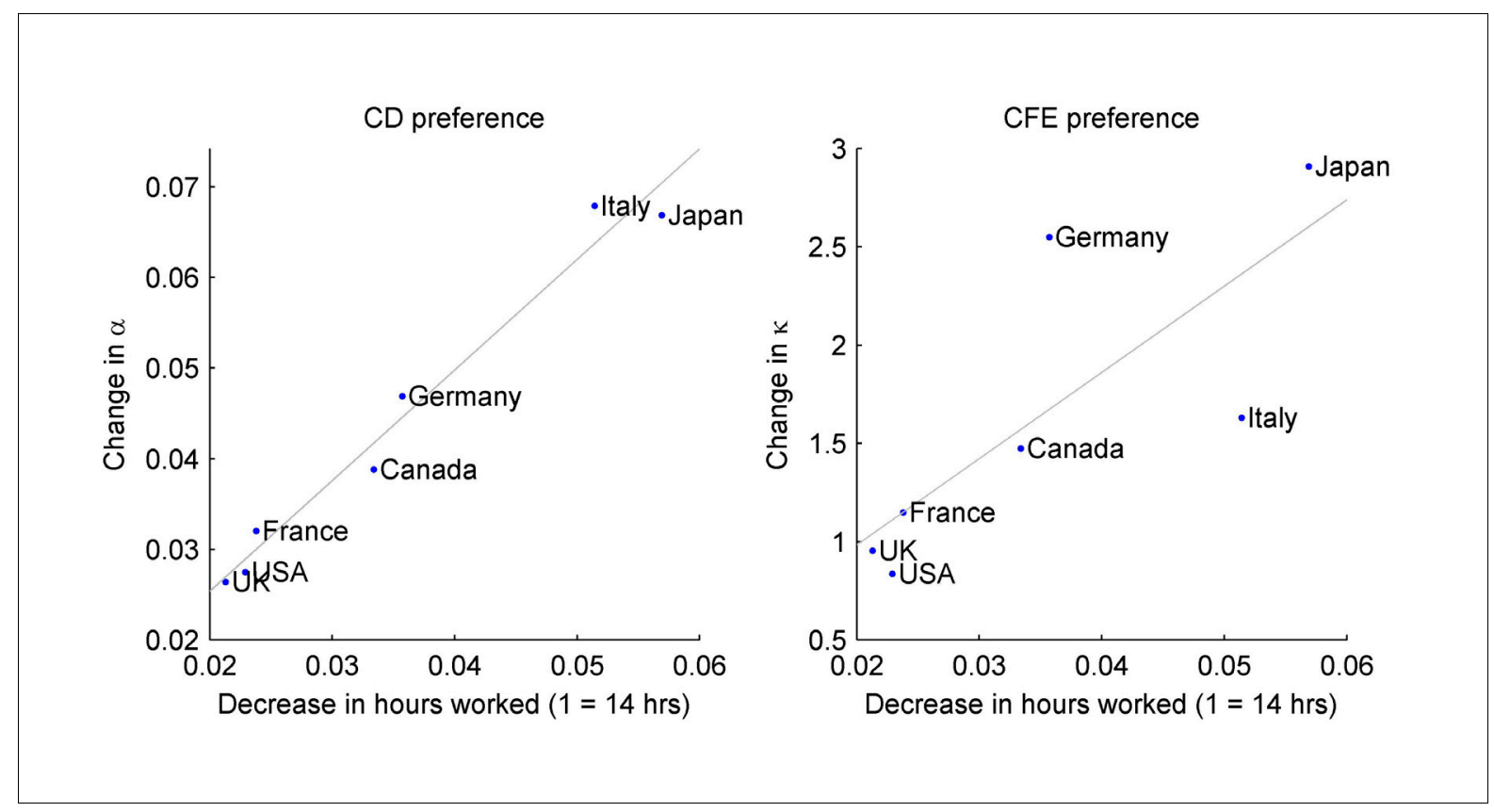


Figure 3. Labor Laffer Curve with CD Preference
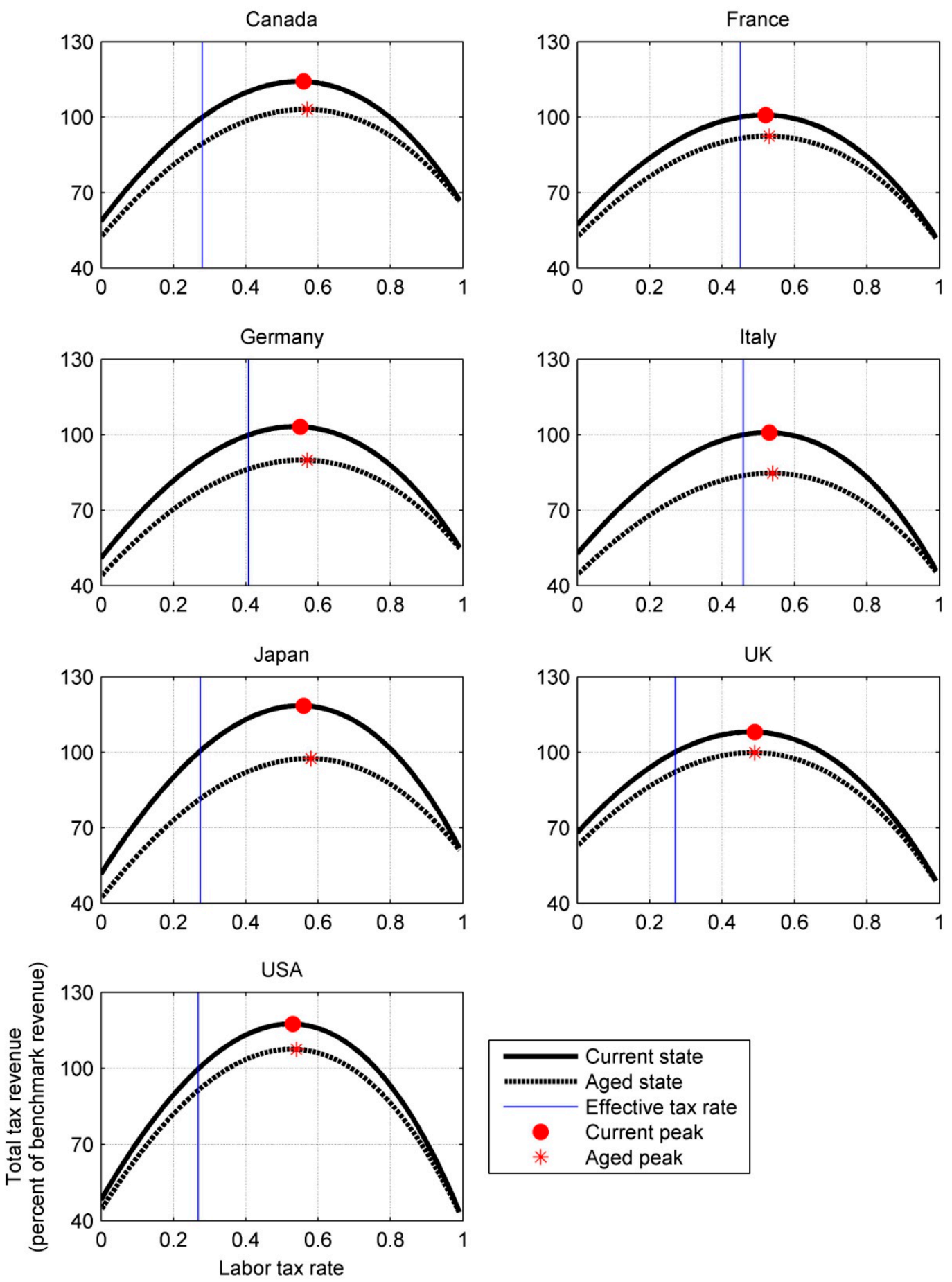
Figure 4. Labor Laffer Curve with CFE Preference
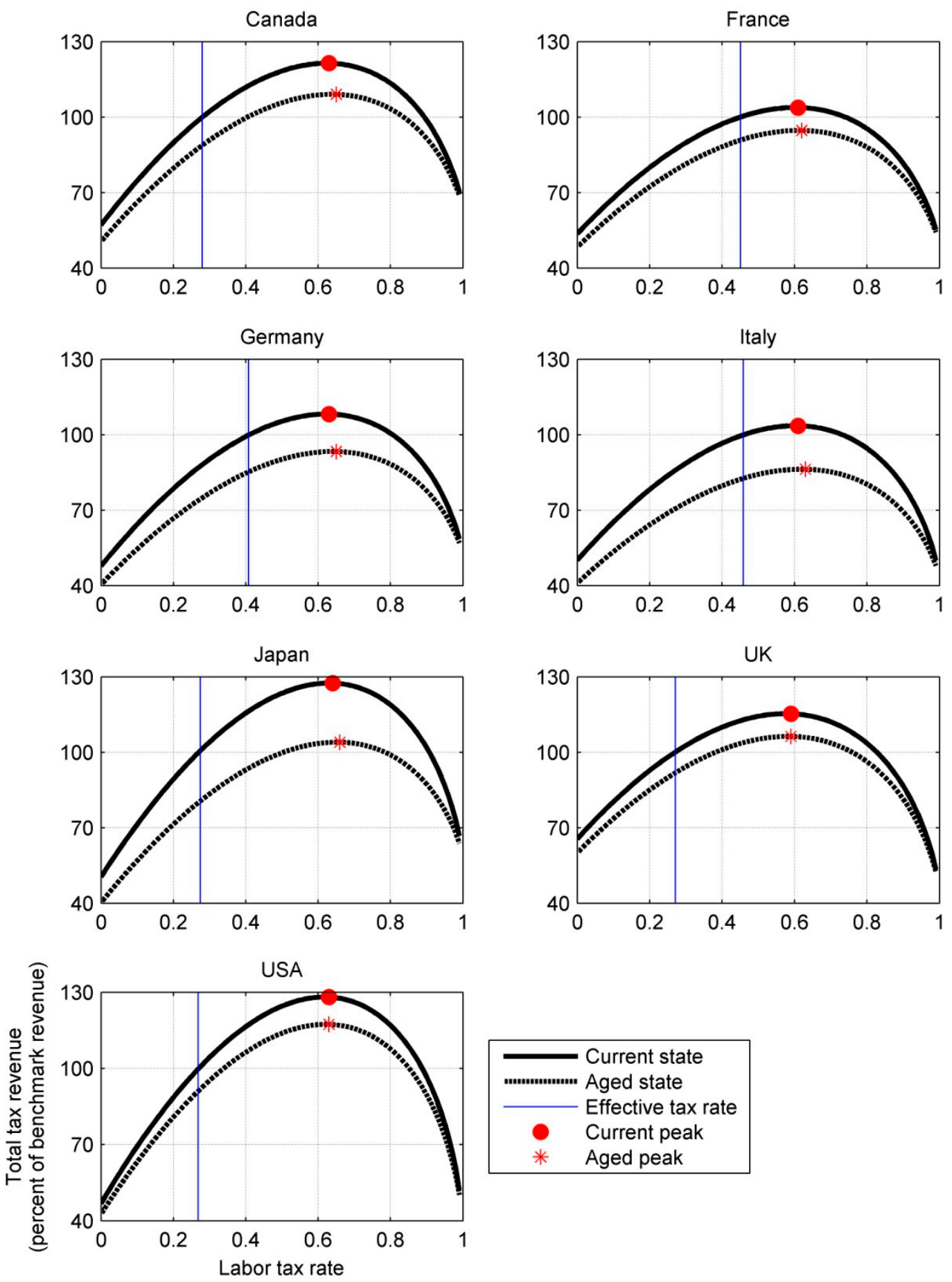
Figure 5. Capital Laffer Curve with CD Preference
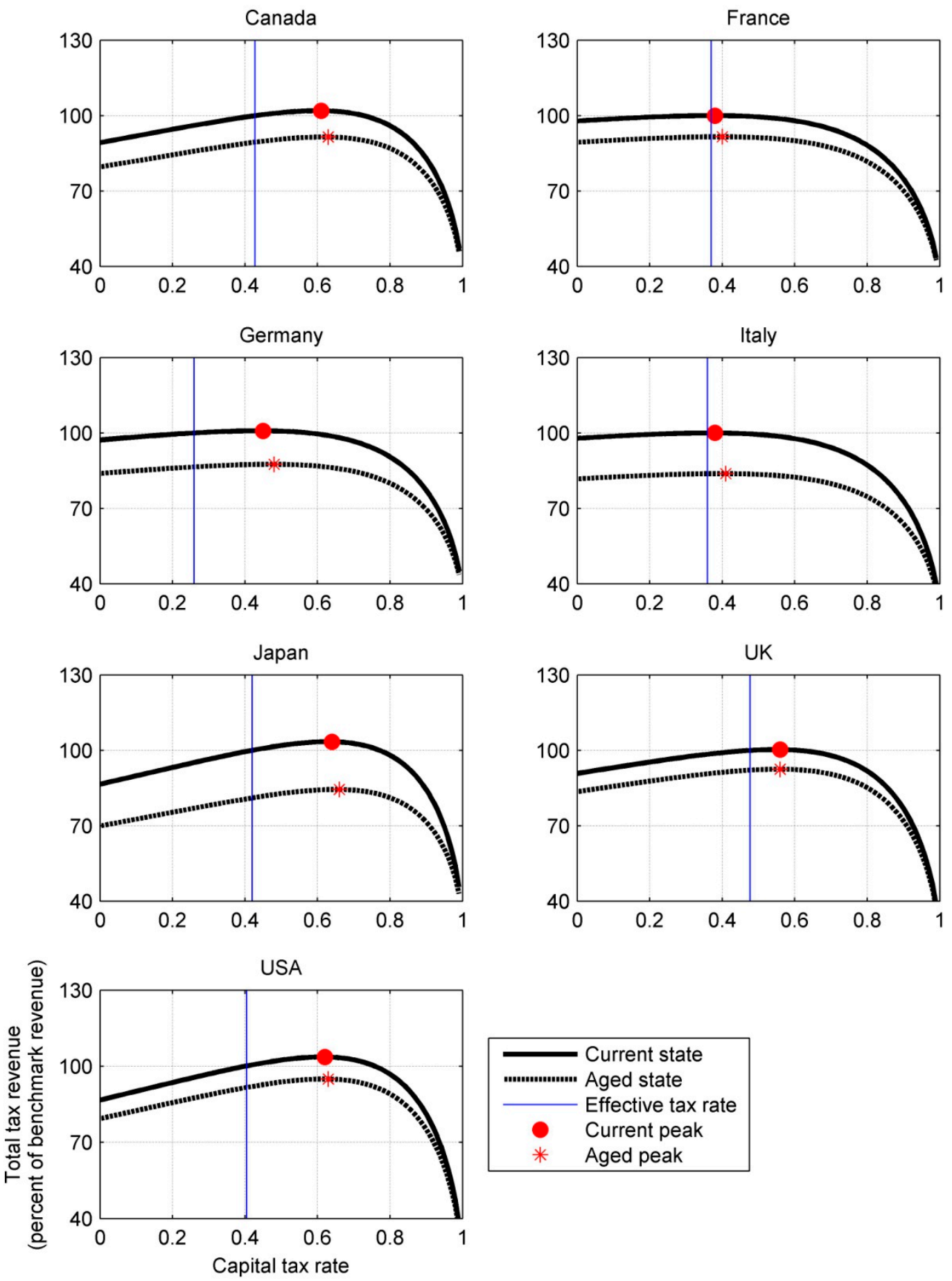
Figure 6. Capital Laffer Curve with CFE Preference
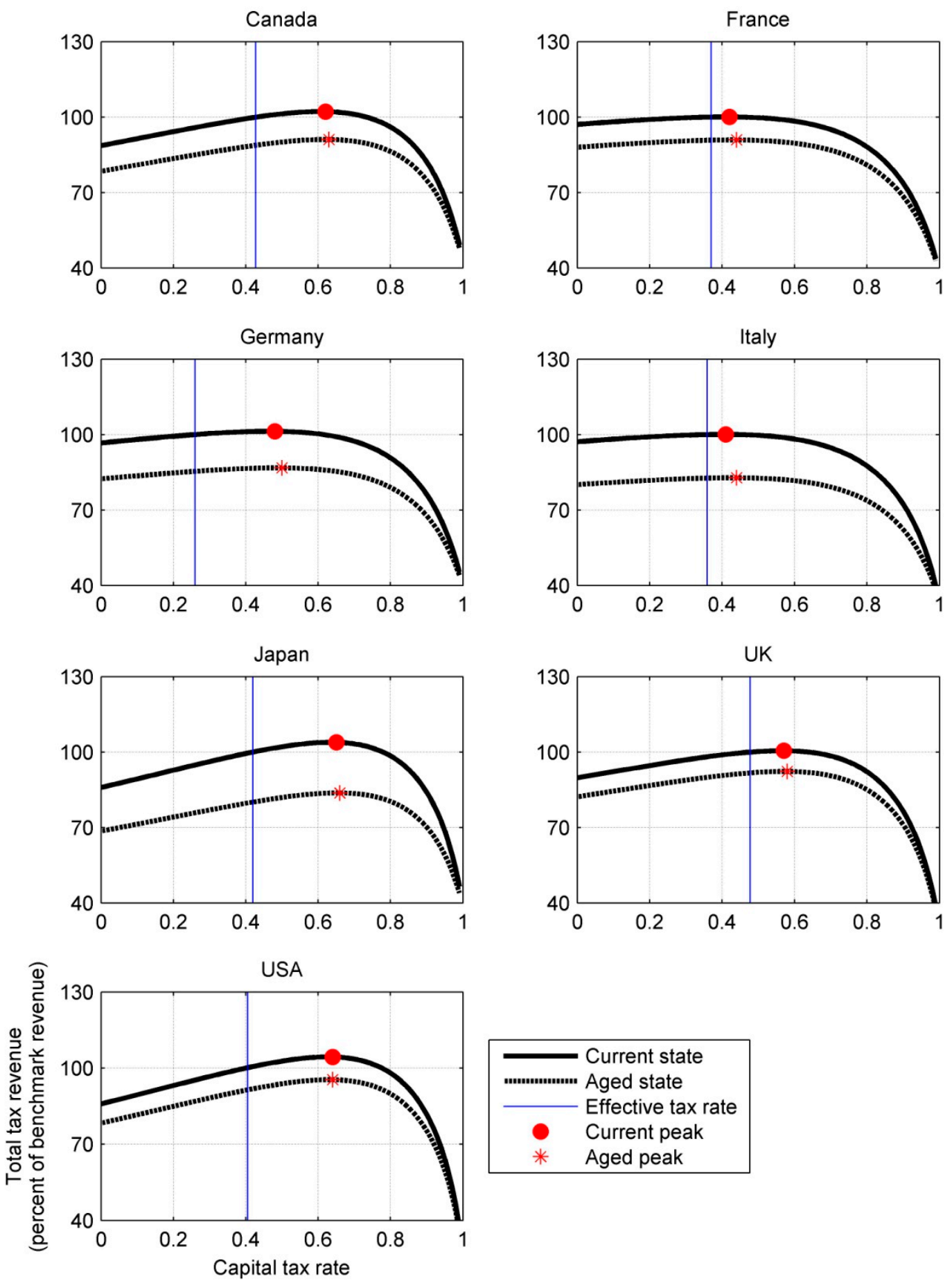
Figure 7. Tax Revenue Decomposition and Tax Bases
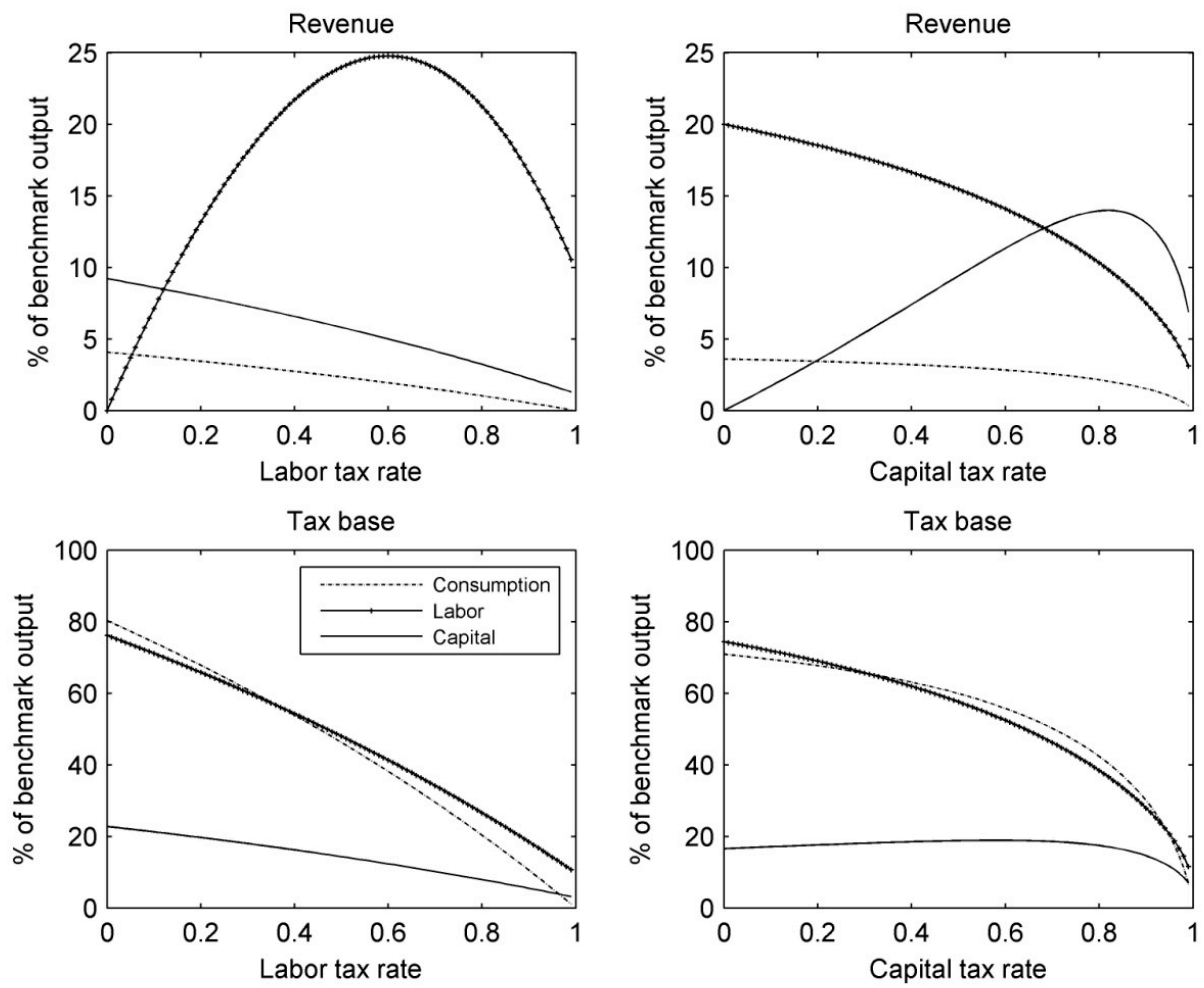

Figure 8. Tax Revenue Ratio, Hours Worked, and Output
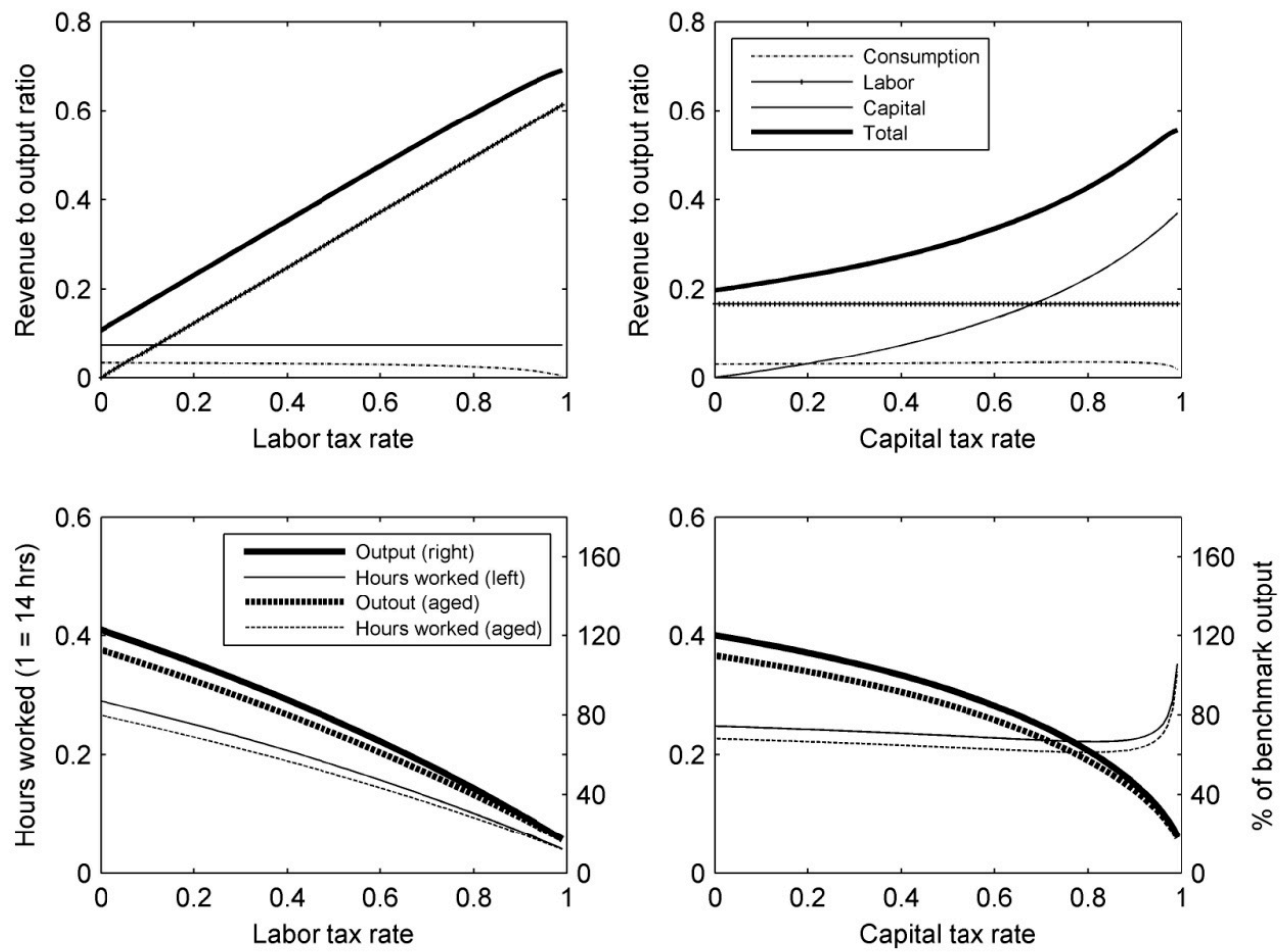

(CInternational Monetary Fund. Not for Redistribution 
Figure 9. Iso-Revenue Curve (CD Preference)
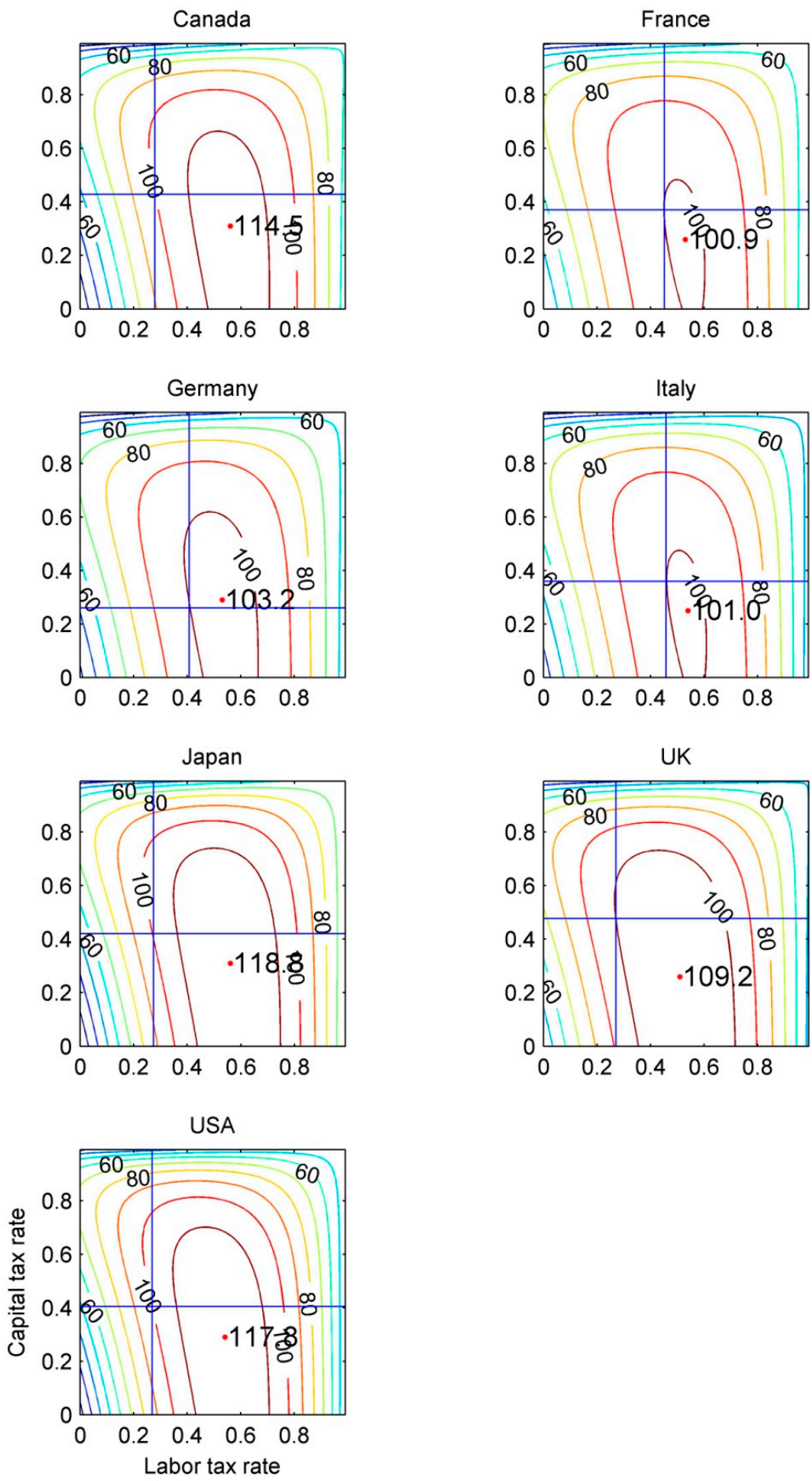
Figure 10. Decrease in Fiscal Space vs. Decrease in Labor Supply
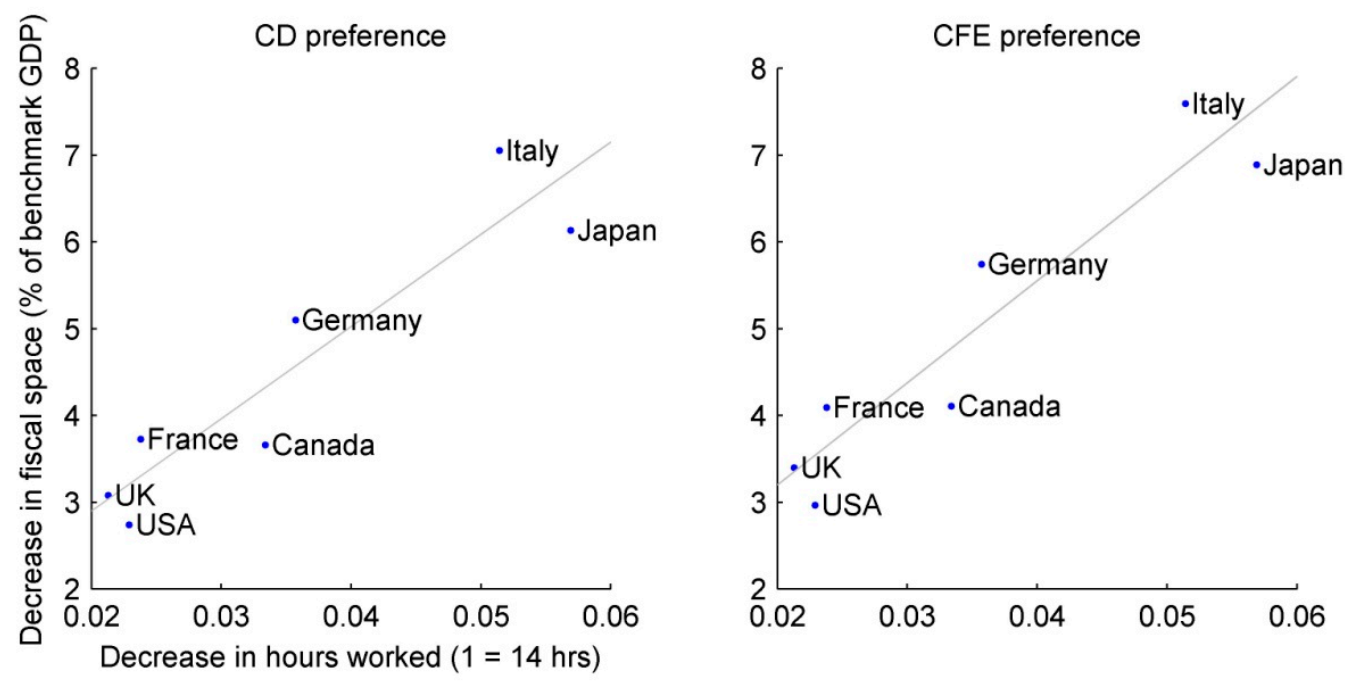


\section{REFERENCES}

Bi, H., 2011, Sovereign Default Risk Premia, Fiscal Limits, and Fiscal Policy, European Economic Review, forthcoming.

Gonzalez-Eiras, M., and D. Niepelt, 2012, Aging, Government Budgets, Retirement, and Growth, European Economic Review 56(1), pp. 97-115.

Karam, P., D. Muir, J. Pereira, and A. Tuladhar, 2010, Macroeconomic Effects of Public Pension Reforms, IMF Working Paper 10/297 (Washington: International Monetary Fund).

Leeper, E.M., and T.B. Walker, 2011, Fiscal Limits in Advanced Economies, Economic Papers: A Journal of Applied Economics and Policy 30(2), pp. 1-15.

Maestas, N., and J. Zissimopoulos, 2010, How Longer Work Lives Ease the Crunch of Population Aging, Journal of Economic Perspectives 24(1), pp. 136-60.

Mendoza, E., A. Razin, and L. Tesar, 1994, Effective Tax Rates in Macroeconomics: CrossCountry Estimates of Tax Rates on Factor Incomes and Consumption, Journal of Monetary Economics 34, pp. 297-323.

Ostry, J., A. Ghosh, J. Kim, and M. Qureshi, 2010, Fiscal Space, IMF Staff Position Note 10/11 (Washington: International Monetary Fund).

Trabandt, M., and H. Uhlig, 2011, The Laffer Curve Revisited, Journal of Monetary Economics 58(4), pp. 305-27. 